\title{
AVALIAÇÃO DAS PROPRIEDADES MECÂNICAS DE BLOCOS INTERTRAVADOS COM RESÍDUO DE PNEU RECICLADO
}

\author{
Anaaiara Varela dos Santos \\ Aluna de Iniciação Científica do Curso de Tecnologia em Construção de Edifícios \\ aninha.varela@hotmail.com \\ Edilberto Vitorino de Borja \\ Professor do Departamento de Construção Civil do CEFET-RN \\ edilberto@cefetrn.br
}

\begin{abstract}
RESUMO
Pavimentos intertravados de concreto são peças pré-moldadas que surgiram visando desenvolver a estrutura de estradas e vias urbanas. As peças pré-moldadas de concreto possuem dimensões e qualidades padronizadas, exigindo alto controle no processo de fabricação. No entanto, sua aplicação é de fácil manuseio, não necessitando de mão de obra especializada. O principal objetivo desta pesquisa foi o de estudar a viabilidade da utilização de resíduos de pneus reciclados em blocos para pavimentos intertravados para calçadas. Partindo-se de um traço de referência, fez-se a caracterização dos materiais componentes da mistura (cimento, areia média e pedrisco) para a confecção de corpos-deprova cilíndricos de $10 \times 20 \mathrm{~cm}$. Em seguida, procedeu-se a moldagem de corpos de prova com a substituição do agregado miúdo por adições do resíduo de pneu nas porcentagens de 10\%, 20\% e 30\%, em massa. Investigou-se nas amostras os parâmetros de Massa Específica e Resistência à Compressão. Analisou-se, de forma comparativa, os resultados obtidos nos corpos-de-prova de referência com os confeccionados com pneu. Verificou-se que até o limite de 30\% de resíduo de pneu, a mistura apresentou trabalhabilidade e coesão, atingindo uma resistência à compressão de $12 \mathrm{MPa}$. Tal valor pode ser considerado elevado em se tratando de blocos que serão usados apenas em calçadas, onde o tráfego será exclusivo de pedestres.
\end{abstract}

Palavras-chaves: pavimentos intertravados, reciclagem, resíduos de pneus e concretos pré-moldados. 


\section{AVALIAÇÃO DAS PROPRIEDADES MECÂNICAS DE BLOCOS INTERTRAVADOS COM RESÍDUO DE PNEU RECICLADO}

\section{INTRODUÇÃO}

Desde a década de 1980, com a disponibilidade no mercado de equipamentos de grande produtividade e com elevado grau de precisão dimensional, a indústria de pavimentos de peças pré-moldadas de concreto - PPC - vem crescendo em grandes proporções em todo o mundo, inclusive no Brasil. O que era um tipo de material utilizado apenas em áreas que demandavam efeitos arquitetônicos ou paisagísticos, deu lugar a um material único e extremamente versátil para harmonizar qualquer tipo de pavimento, inclusive o industrial e rodoviário, tanto esteticamente quanto estruturalmente, o pavimento intertravado.

Outra característica de destaque neste tipo de pavimento é sua manutenção, que ao contrário de outros tipos de pavimento que demandam equipamentos dispendiosos, pode ser realizada com uma pequena equipe e ferramentas manuais.

O pavimento de peças pré-moldadas de concreto (designado por PPC), hoje denominado de pavimento intertravado, é uma nova técnica de pavimentação e é uma opção para o desenvolvimento do setor rodoviário e urbano do país. Pavimentos, como o intertravado, que necessitam de mão de obra não especializada para a confecção de sua estrutura e, principalmente, da sua camada de revestimento, devem começar a ser vistos com outros olhos pelos órgãos públicos, responsáveis pela pavimentação de vias. Além de proporcionarem melhorias estéticas, técnicas e de redução de custos para os transportes, em vias não pavimentadas, geram a utilização intensa de mão de obra local, proporcionando um aumento da receita familiar com a geração de novos empregos.

À medida que este tipo de pavimento deixou de ser uma opção somente arquitetônica e paisagística, foi necessário o desenvolvimento de novos estudos e pesquisas sobre o mesmo, inclusive em relação à utilização de novos materiais que podem ser adicionados durante o processo de preparação das peças pré-moldadas de concreto.

Percebendo a importância deste tipo de pavimento aliada a necessidade de promover um destino nobre ao resíduo de pneu reciclado, que já vem sendo objeto de estudo em outros trabalhos do Núcleo Pesquisa de Construção Civil do CEFET/RN, surgiu a possibilidade de se estudar a utilização desse resíduo em pavimentos intertravados, como uma alternativa para minimizar os impactos ambientais advindos do pneu. A pesquisa está voltada para o uso de blocos de pavimentos intertravados para uso exclusivo em calçadas, cujo tráfego predominante será o de pedestres, uma vez que não se exige grandes valores de resistências mecânicas, porém serão observadas as exigências normativas para as demais propriedades do material. Nesta etapa inicial, moldou-se corpos-de-prova cilíndricos de $10 \times 20 \mathrm{~cm}$ para todos os traços estudados (com e sem resíduo de pneu) analisando-se comparativamente os resultados de absorção de água, massa específica, porosidade e resistência à compressão. Salienta-se que a pesquisa terá continuidade com a moldagem de blocos em formato usual de utilização, para análise das demais propriedades necessárias para sua completa caracterização e conclusão do estudo. 


\section{METODOLOGIA}

O trabalho foi iniciado com a realização de pesquisas bibliográficas (livros e páginas de internet), sobre os materiais que seriam utilizados: cimento, areia, pedrisco, resíduos de pneu e água, relacionados com pavimentos intertravados.

A realização da pesquisa iniciou-se com a coleta do resíduo de pneu nas indústrias recauchutadoras de pneus na Ribeira-Natal/RN e com a coleta dos demais materiais (cimento, areia e pedrisco) dentro da instituição (CEFET/RN), provenientes de obras de reforma e ou ampliação. Após a coleta dos materiais, foram realizados ensaios para caracterização, tais como: massa unitária, massa especifica e granulometria. Tais parâmetros são necessários para cálculos das quantidades dos materiais para confecção dos corpos-de-prova. Não houve variação dos materiais durante todo o desenvolvimento da pesquisa.

Após a definição do traço de referência e com base em pesquisas bibliográficas, optou-se pela substituição parcial da areia pelo resíduo de pneu nas proporções, em massa, de $10 \%$, $20 \%$ e $30 \%$.

A tabela 1 ilustra as quantidades dos materiais necessários para moldagem de 9 corpos de prova cilíndricos de $10 \mathrm{~cm}$ de diâmetro por $20 \mathrm{~cm}$ de altura para cada formulação, incluindo o traço de referência e os outros 3 com acréscimos de pneu nas proporções acima citadas.

Tabela 1 - Quantidades dos Materiais, em g.

\begin{tabular}{c|c|c|c|c|c|c}
\hline Designação & $\begin{array}{c}\text { \% de } \\
\text { resíduo }\end{array}$ & Cimento & Areia & Pedrisco & Pneu & Água \\
\hline TR & $0 \%$ & 9033 & 10749 & 10749 & - & 4000 \\
\hline T10 & $10 \%$ & 9033 & 9675 & 10749 & 1074 & 4000 \\
\hline T20 & $20 \%$ & 9033 & 8599 & 10749 & 2150 & 4000 \\
\hline T30 & $30 \%$ & 9033 & 7524 & 10749 & 3225 & 4000 \\
\hline
\end{tabular}

Para a mistura dos materiais utilizou-se de uma betoneira com capacidade de 120 litros. Em seguida, os corpos-de-prova de concreto foram moldados em moldes metálicos de 10 $\mathrm{cm}$ de diâmetro por $20 \mathrm{~cm}$ de altura. Distribuiu-se o concreto no molde em 4 camadas. Cada camada recebeu 30 golpes distribuídos uniformemente ao longo de toda superfície. Após moldagem, foram colocados placas de vidros nas superfícies dos corpos-de-prova por um período de $24 \mathrm{~h}$ no intuito de evitar a perda de água durante o processo de cura inicial. Decorrido 24h, as amostras foram completamente submersas em tanques com água até o dia de seu rompimento. Para cada traço, moldaram-se 9 corpos-de-prova (figura 1). As amostras foram ensaiadas com 1dia, 3 dias, 7 dias e 28 dias de idade; Todos os ensaios de moldagem, processo de cura e rompimento das amostras foram realizados em acordo com as normas brasileiras vigentes pertinentes ao assunto. 


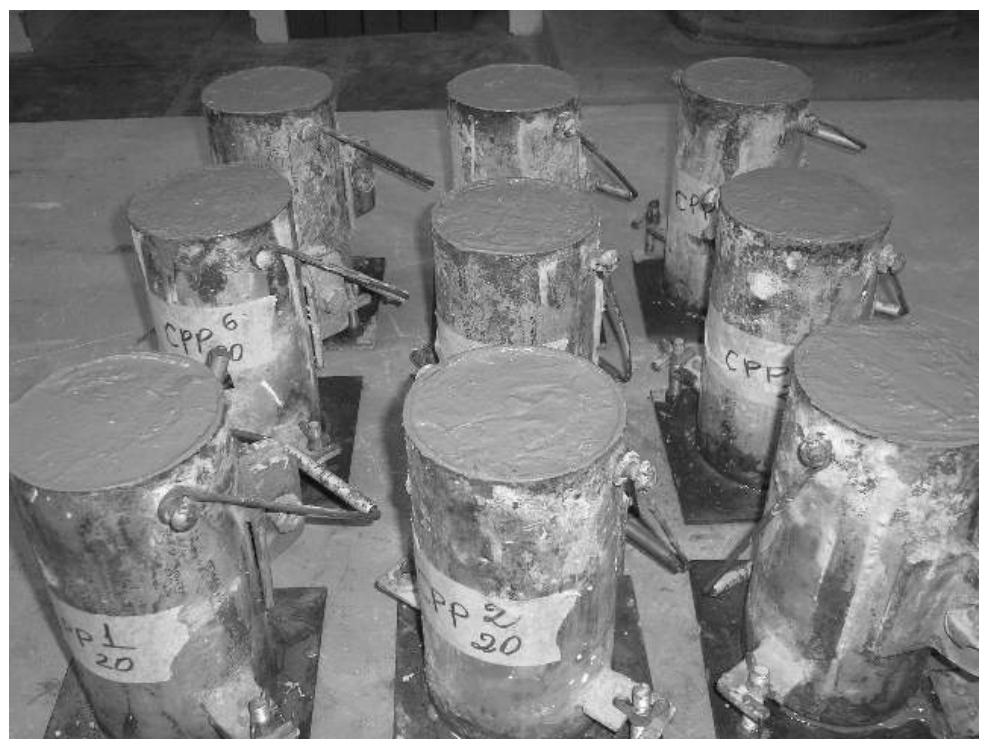

Figura 1 - Corpos de prova moldados com traço de referência

\section{MATERIAIS}

Para todos os blocos confeccionados com todas as formulações utilizou-se do mesmo tipo de cimento Portland CP II - Z 32 RS , da mesma marca; Areia proveniente de lagoa localizada no distrito de Igrejinha, município de Macaíba; Brita de rocha granítica extraídas da região de Monte Alegre, e resíduo de pneu coletados das renovadoras de pneus na cidade de Natal/RN, no bairro da Ribeira. Na tabela 2 ilustram-se os resultados obtidos nos ensaios de massa específica e massa unitária dos materiais usados na pesquisa.

Tabela 2 - Massa unitária e específica dos materiais utilizados.

\begin{tabular}{c|c|c}
\hline Materiais & $\begin{array}{c}\text { Massa Unitária } \\
\left(\mathbf{g} / \mathbf{c m}^{3}\right)\end{array}$ & $\begin{array}{c}\text { Massa específica } \\
\mathbf{( g / \mathbf { c m } ^ { 3 } )}\end{array}$ \\
\hline Cimento & 1,07 & 3,05 \\
\hline Areia & 1,55 & 2,60 \\
\hline Pedrisco & 1,49 & 2,66 \\
\hline Resíduo Pneu & 0,35 & 1,19 \\
\hline
\end{tabular}

A moldagem e procedimentos de ensaios se deu em consonância com as normas brasileiras vigentes. Para determinação da massa específica do resíduo de pneu utilizou-se o método do picnômetro com substituição da água pelo querosene. A adoção do querosene deve-se ao fato do mesmo possuir densidade inferior à água $\left(0,8 \mathrm{~g} / \mathrm{cm}^{3}\right)$. Os demais procedimentos foram regidos pela norma NBR 9937;

Os ensaios granulométricos feitos com os agregados foram baseados nas normas NBR 7217. Na tabela 3 apresentam-se os módulos de finura e os diâmetros máximos. Nas figuras 2, 3 e 4 ilustram-se as curvas granulométricas da areia, pedrisco e resíduo de pneu, respectivamente. 
Tabela 3 - Parâmetros obtidos no ensaio de granulometria dos agregados.

\begin{tabular}{c|c|c}
\hline Materiais & Módulo de Finura & $\begin{array}{c}\text { Diâmetro Máximo } \\
(\mathbf{m m})\end{array}$ \\
\hline Areia & 2,37 & 2,40 \\
\hline Pedrisco & 5,75 & 9,50 \\
\hline Resíduo Pneu & 3,46 & 4,80 \\
\hline
\end{tabular}

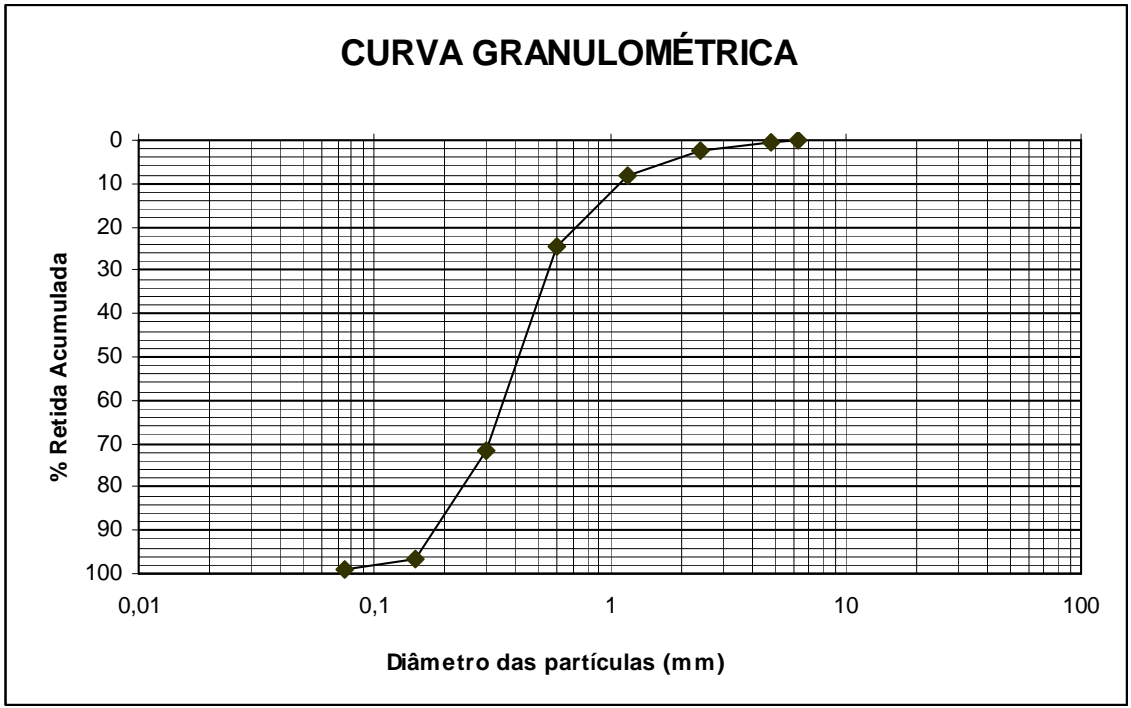

Figura 2 - Curva granulométrica da areia.

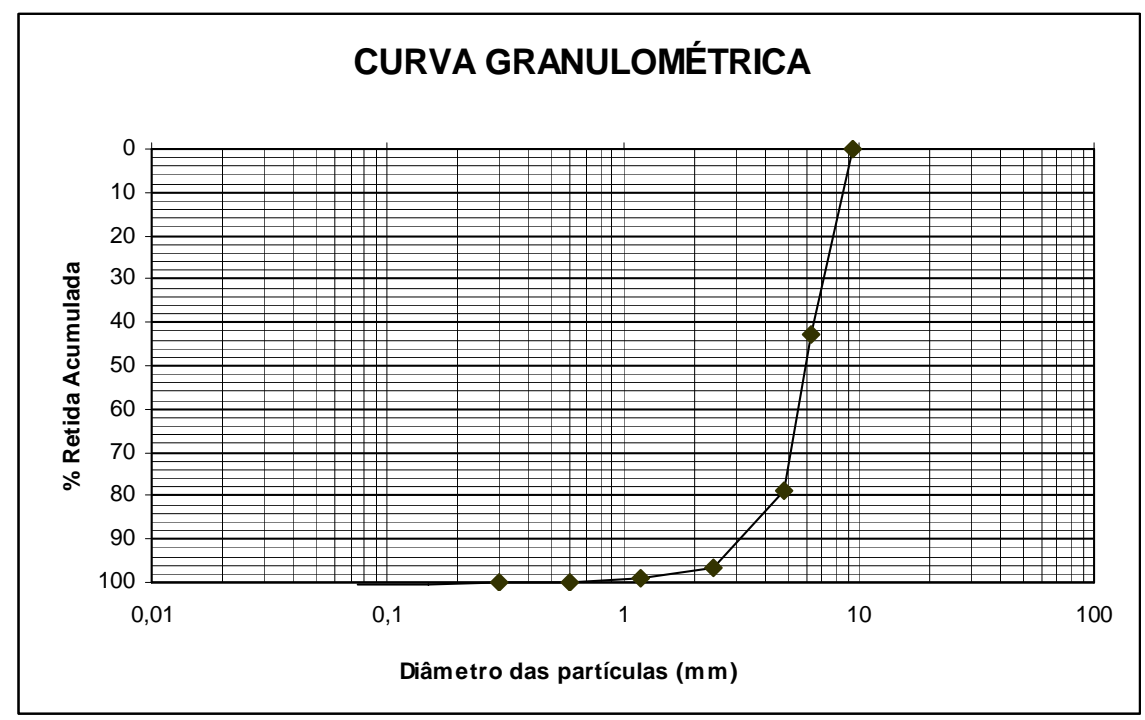

Figura 3 - Curva granulométrica do pedrisco. 


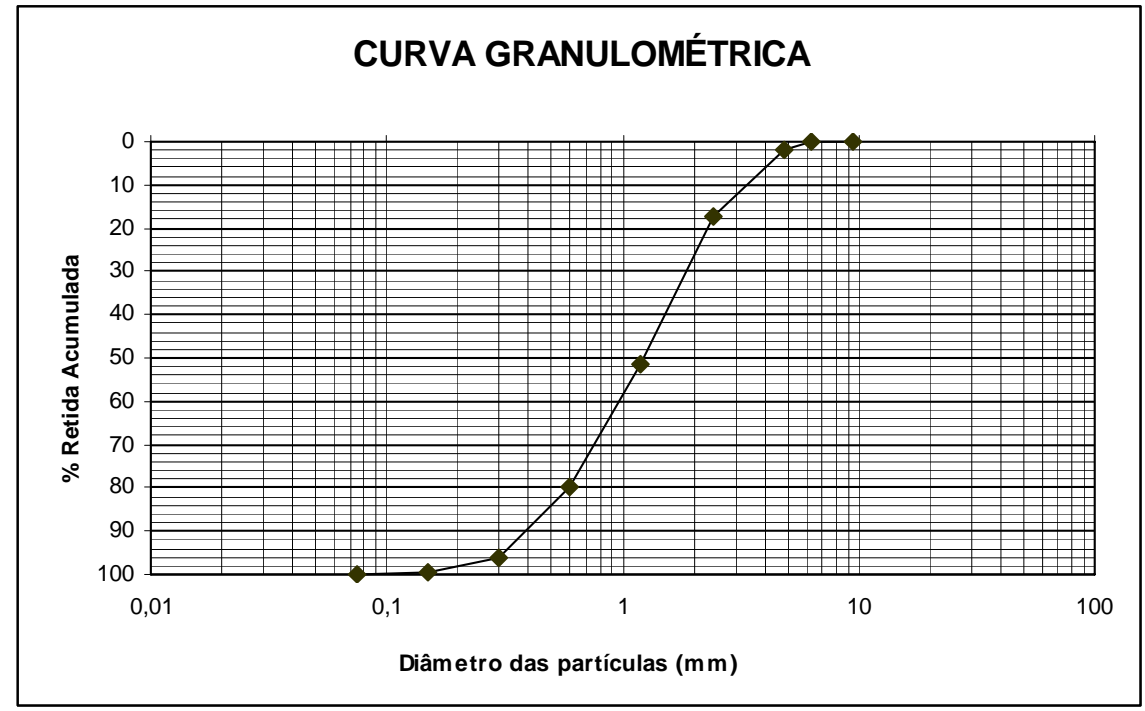

Figura 4 - Curva granulométrica do resíduo de pneu.

\section{RESULTADOS}

Para cada formulação estudada, moldaram-se 9 (nove) corpos de prova cilíndricos $(10 \mathrm{~cm} \times 20 \mathrm{~cm})$, totalizando 36 corpos de prova (CP). Foram determinadas as massas específicas e a resistência à compressão para as idades de 1 dia, 3 dias, 7 dias e 28 dias, com as quantidades de amostras distribuídas da seguinte forma: 2 CP's para serem ensaiados com 1 dia, 2 CP's para 3 dias, 2 CP's para 7 dias e os últimos 3 CP's ensaiados com 28dias. A sigla CP é usada para designar Corpos de Prova.

Na figura 5 ilustram-se as massas específicas dos CP's com relação as porcentagens de resíduo. Observa-se que a medida que aumentamos o percentual de resíduo na mistura, a massa específica reduz. Fato este já esperado, uma vez que temos substituição de um material mais denso (areia) por outro de densidade bastante inferior (resíduo de pneu). Nota-se também que a partir do terceiro dia após moldagem, a variação da massa específica permanece praticamente constante. Este tipo de comportamento foi uniforme para todas as formulações, inclusive para o de referência, inferindo-se que a presença do resíduo não ocasiona alterações no processo de endurecimento do cimento. 


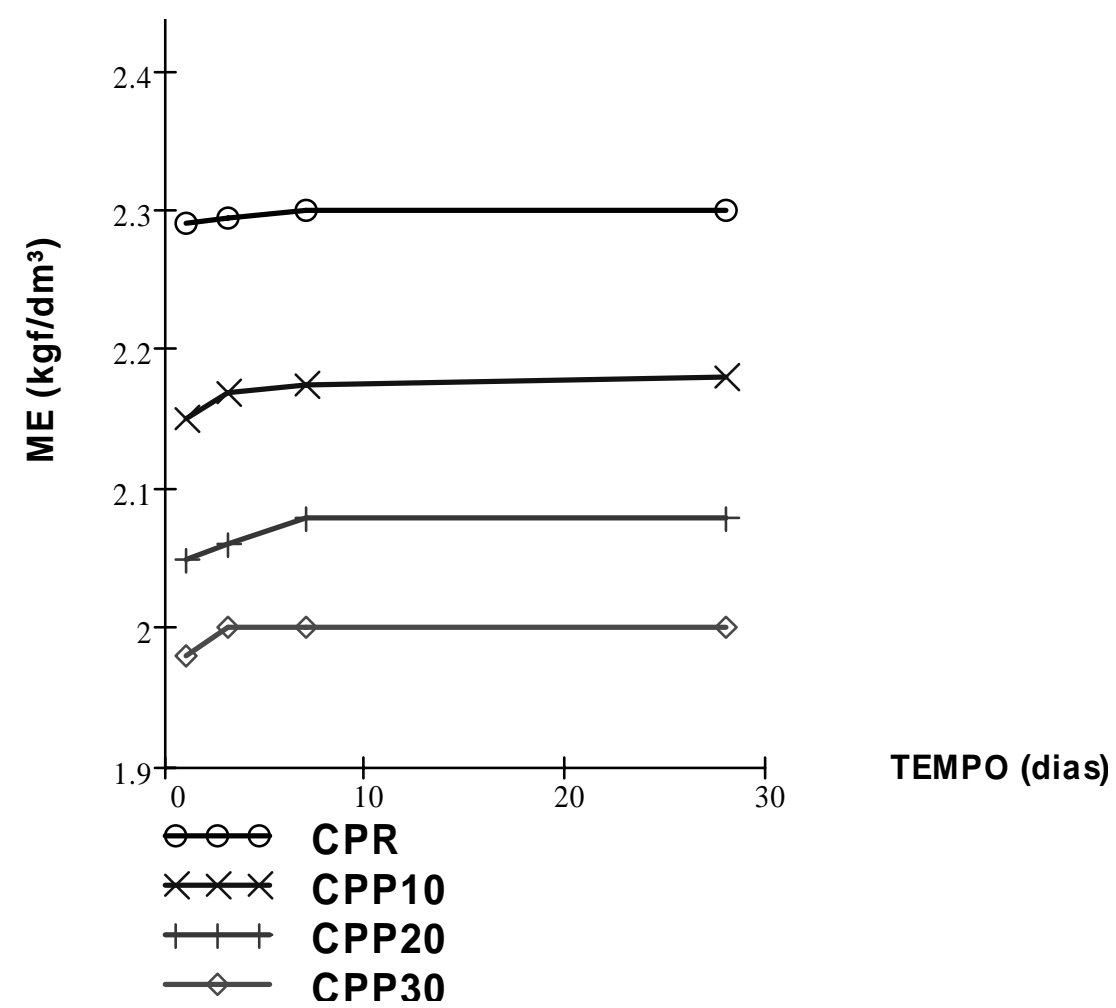

Figura 5 - Massa específica em função do tempo (dias)

Onde: $\quad$ CPR - corpos de prova de referência;

CPP10 - corpos de prova com $10 \%$ de resíduo;

CPP20 - corpos de prova com 20\% de resíduo;

CPP30 - corpos de prova com 30\% de resíduo.

Na figura 6 evidenciam-se as resistências à compressão dos CP's com relação as porcentagens de resíduo. Observa-se que a evolução de resistência das amostras para uma mesma formulação obedece a escala de crescimento encontradas nas literaturas técnicas referentes ao assunto. Fato este que se repete para todas as formulações estudadas. Percebe-se ainda, como na massa específica, uma redução de resistência à compressão a medida que aumentamos a quantidade de resíduo. 


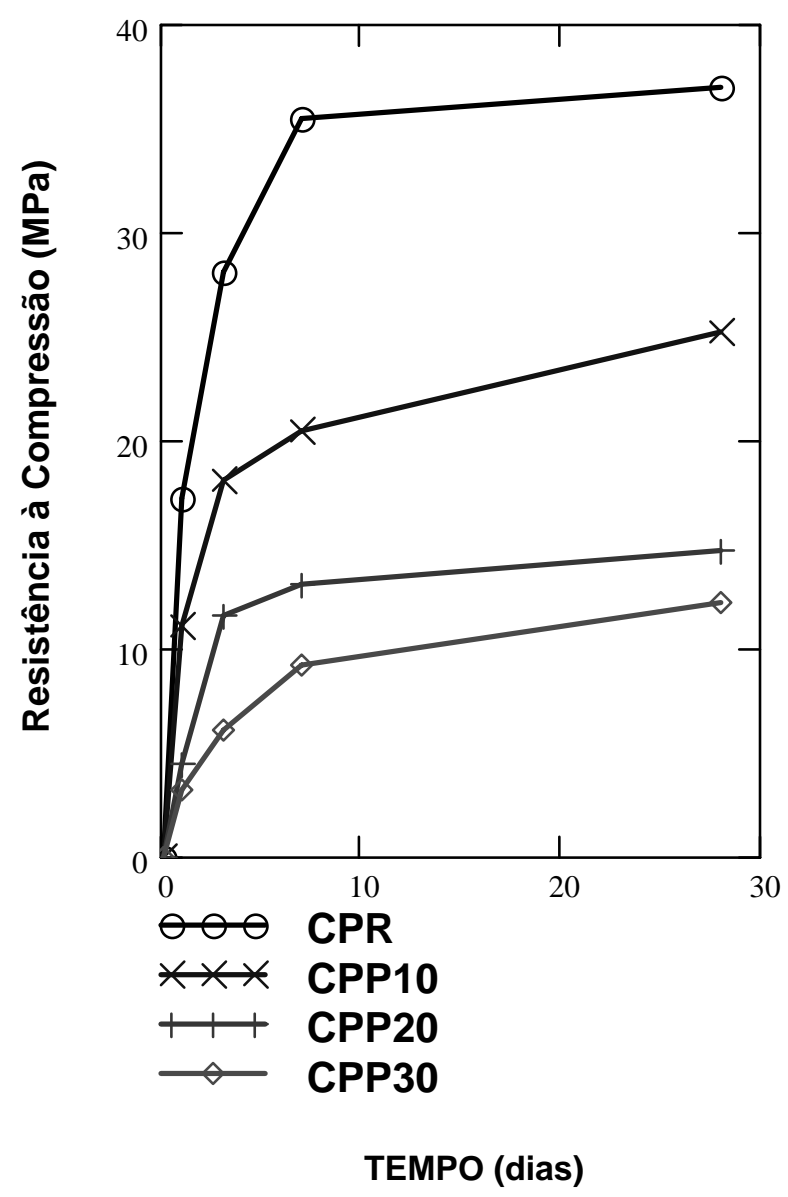

Figura 6 - Resistência à compressão em função do tempo (dias).

\section{CONCLUSÕES}

Com base na análise dos resultados obtidos verificou-se que:

- A adição do resíduo de pneu na mistura do concreto resultou na diminuição da resistência à compressão dos corpos de prova de concreto. Dado este comprovado pelo gráfico da resistência a compressão apresentado acima, onde se percebe que à medida que a porcentagem de resíduo de pneu era acrescida à mistura, sua resistência apresentava um valor menor ao anterior. No traço feito sem a adição de resíduo de pneu, a resistência atingida foi de $38 \mathrm{MPa}$. Em significante contraste com esse valor, a resistência do traço feito com 30\% de resíduo de pneu atingiu 12 $\mathrm{MPa}$

- É viável a utilização de blocos de concreto para pavimentos intertravados com a adição de resíduo de pneus com resistência de 12 Mpa. Porém, essa resistência ainda pode ser considerada elevada visto que, no que diz respeito a blocos de concreto que serão utilizados em calçadas, o tráfego será destinado apenas aos pedestres, sendo desnecessária uma resistência alta.

- O acréscimo do resíduo de pneu tornou o concreto, no seu estado fresco, mais elástico, resultando na diminuição de sua plasticidade.

- A quantidade de resíduos adicionados à mistura de concreto influenciou na sua massa específica, deixando-o mais leve. 


\section{REFERÊNCIAS}

Associação Brasileira de Normas Técnicas. NBR 9780 - Peças de concreto para pavimentação - determinação da resistência á compressão - método de ensaio - 1987. . NBR 9781 - Peça de concreto para pavimentação - especificação - 1987 . NBR 7211 - Agregado para concreto - especificação - 2005 . NBR 5736/5737. Cimento portland pozolanico - especificação - 1991 NBR 7251. Agregado em estado solto - Determinação da massa unitária - 1982.

\section{AGRADECIMENTOS}

- Ao Departamento de Pesquisas do CEFET-RN;

- Ao Departamento Acadêmico de Construção Civil;

- Aos integrantes do Núcleo de Pesquisas;

- Votorantin - Cimentos Poty. 